процесс совершенствования техники прогнозирования, обеспечения точности прогнозов. Это подтверждается и использованием в процессе управлении стратегического, индикативного планирование, и возникновение и внедрение программных решений для разработки прогнозов. Поэтому для совершенствования механизма управления социальноэкономическим развитием региона, необходимо создать условия для формирования качественного прогноза социально-экономических параметров.

$$
* * *
$$

1. Прогноз долгосрочного социально-экономического развития Российской Федерации на период до 2030 года (разработан Минэкономразвития России).

2. Лексин В.Н., Швецов А.Н.. Реформы и регионы: Системный анализ процессов реформирования региональной экономики, становления федерализма и местного самоуправления. - М.: ЛЕНАНД, 2012г.

\title{
Сабитова К.А. \\ Угрозы конкурентоспособности компаний в условиях трансформации цифровой экономики
}

Пензенский государственньй технологический университет

(Россия, Пенза)

doi: 10.18411/trnio-12-2021-57

Научный руководитель Ильясова А.В.

\section{Аннотация}

В статье представлен анализ факторов конкурентоспособности в условиях цифровой экономики. Автор рассматривает конкурентоспособность в макроэкономическом масштабе на уровне государства и в масштабе отдельного предприятия. В глобальном аспекте были проанализированы данные Всемирного экономического форума в отношении расчета глобального индекса конкурентоспособности.

Особое внимание уделено трансформации факторов конкурентоспособности в условиях цифровой экономики. С позиции предприятия отмечена взаимосвязь его конкурентоспособности с макроэкономическими факторами и трансформацией бизнеспроцессов и бизнес-моделей в цифровую форму.

Ключевые слова: конкурентоспособность, факторы конкурентоспособности, цифровая экономика, механизмы управления конкурентоспособностью, информационная экономика.

\section{Abstract}

The article presents an analysis of the factors of competitiveness in the digital economy. The author considers competitiveness on a macroeconomic scale at the state level and at the scale of an individual enterprise. In the global aspect, the data of the World Economic Forum on the calculation of the global competitiveness index were analyzed. Special attention is paid to the transformation of competitiveness factors in the digital economy. From the position of the enterprise, the relationship of its competitiveness with macroeconomic factors and the transformation of business processes and business models into digital form is noted.

Keywords: competitiveness, competitiveness factors, digital economy, competitiveness management mechanisms, information economy.

Проявление результатов становления цифровой экономики находит свое отражение на всех уровнях хозяйствования, кардинально изменяется характер функционирования процессов как на уровне домохозяйств и организаций, так и на уровне различных стран. Некоторые страны можно назвать цифровыми лидерами, другие страны еще стоят на пороге активного использования новейших инновационных достижений [1]. 
Цифровая экономика может определяться как управляемая система социальноэкономических отношений, в которой вовлечение ресурсов, взаимодействие субъектов и объектов, а также получение полезного результата обеспечиваются путем обмена цифровыми данными о параметрах и свойствах каждого элемента системы с помощью информационно-коммуникационных технологий [4].

Гипотезой исследования является утверждение о том, что на сегодняшний день многие традиционные методы оценки конкурентоспособности являются устаревшими и малоэффективными в условиях активно развивающейся экономики шестого технологического уклада.

Цель данной работы заключается в выявлении факторов оценки конкурентоспособности, актуальных для современной цифровой экономики.

Методами, применяемыми в данной работе, являются систематизация информации о факторах, используемых при определении уровня цифровой трансформации различных сфер экономики как в РФ, так и за рубежом; анализ существующих методов оценки конкурентоспособности субъектов хозяйствования.

В последние несколько лет многие люди говорят о цифровой экономике, потому что они предполагают, что процесс цифровизации вскоре приведет к новой эре «Цифровой революции». В то же время общество сейчас разделено на два класса: те, кто считает, что необходимо продвигать цифровую экономику в массы, и те, кто считает, что это приведет к ухудшению финансового состояния общества в связи с переходом на новый уровень производства. Я предлагаю рассмотреть все плюсы и минусы цифровой экономики.

В первую очередь рассмотрим положительные стороны цифровой экономики повышения конкурентоспособности экономики.

1. Повышение производительности труда и повышение эффективности использования ресурсов.

Производительность труда является одним из критериев влияния цифровизации на отрасль. Наряду с появлением новых производственных технологий, которые оптимизируют работу многих сотрудников, количество рабочих мест будет соответственно сокращено за счет способности, например, одного человека, использующего компьютер, выполнять работу за десять одних и тех же специалистов.

С точки зрения предпринимателя это звучит очень заманчиво, ведь чем ниже издержки производства, тем больше финансовый результат. Но если посмотреть с другой стороны (со стороны сотрудника), картина выглядит не столь многообещающей, потому что логично, что штат многих предприятий будет сокращен вместе с приходом цифровизации. Возникает вопрос: «Когда произойдет переход предприятий на цифровые технологии и предприниматель больше не будет нуждаться в услугах своих сотрудников?».

Сейчас много говорят о том, что этого определенно не произойдет в ближайшие десять лет и переход, скорее всего, будет плавным и равномерным. Одновременно будет проведен комплекс мероприятий, способствующих обновлению и дополнению знаний сотрудников, то есть подготовке и переподготовке уже квалифицированных специалистов.

2. Повышение уровня инновационного развития компаний.

Переход производителей на новый уровень производства приведёт компании к инновационным методам управления, более эффективным для производства, чем те, которые использовались до этого и используются в наше время. Это в первую очередь связано с рядом возникновения новых сложностей в ведении хозяйства. Со временем переход на новую систему управления позволит менеджменту реализовывать процесс управления производством исходя из статистических и аналитических данных, что позволит более конкретно понимать какой продукт нужен потребителю. Эти данные производитель будет получать не только из опыта и статистики прошлых лет работы, но и благодаря современным методам. Информацию о потребностях того или иного покупателя можно будет получить из всемирной паутины, просто прослеживая за теми запросами, которые мы (потребители) делаем в Интернете ежедневно, из чего, в последствии, будет складываться уже новая 
статистика, говорящая производителю о том, какой продукт производить, в каких количествах и какого качества, и еще множество других факторов [5].

3. Снижение издержек производства.

Новая экономика позволит всем производителям снизить издержки производства своего предприятия. Цифровизация, рано или поздно, привёдет к тому, что процесс производства товаров и услуг будет предсказуем, то есть будет известно и высчитано количество ресурсов, требующихся для создания продукта, точное количество товара, которое точно будет продано и огромное количество другой полезной информации перестанет быть загадкой. Вследствие этого будет происходить снижение издержек производства до минимума, который требуется для создания тех или иных товаров и услуг.

4. Создание новых рабочих мест.

Логично, что с переходом общества к цифровой экономике рынку труда понадобятся квалифицированные специалисты нового уровня, люди, которые смогут не только выполнять порученную им работу, но и будут участвовать в инновационном, творческом процессе: придумывать новые методы работы, адаптировать старый стиль обработки информации к инновационному и многое другое. Прежде всего, миру понадобятся специалисты в области IT-технологий и экономической безопасности, поскольку без этих двух областей существование цифровой экономики априори невозможно.

Заглядывая вперёд, можно предположить, что специалисты именно этого направления будут создавать для нас новые инструменты для использования цифровой экономики. Именно они будут создавать новые платформы для покупок с удобным для использования любым человеком интерфейсом, новые сайты и программы - все это дело рук ITспециалистов [3].

С приходом же цифровой экономики, это количество может только увеличиваться, ибо многие процессы будут происходить онлайн, что вызовет большой интерес у множества мошенников, действующих на просторах всемирной паутины.

Также нужно учитывать, что угроза представляется не только для частных лиц, но также и для огромных корпораций, финансовые потери которых могут насчитываться миллиардами. Актуальность «экономической безопасности» с годами будет только возрастать, что говорит о том, что количество рабочих мест для специалистов данного направления будет только увеличиваться.

Рассмотрев все преимущества цифровой экономики, мы можем с уверенностью сказать, что это очень большой шаг для человечества в будущее, но прежде чем сделать окончательный вывод, необходимо рассмотреть другую сторону новой экономики.

1. Риск киберугроз, связанных с защитой персональных данных.

Сейчас, в 2021 году, в Интернете можно найти огромное количество информации практически о каждом человеке или организации: возраст, семейное положение, место работы и многое другое - все это можно узнать, просто просмотрев страницы в любой социальной сети. А как насчет денежных счетов? Сегодня довольно сложно украсть деньги с чьего-либо банковского счета, возможно, только путем мошенничества, с помощью определенных схем мошенникам удается списывать деньги с чужих карт. Существуют также кибератаки на огромные корпорации, целью которых является не только присвоение злоумышленниками чужих средств, но и, например, выведение из строя сложных систем, что влечет за собой большие убытки для предприятий. С приходом цифровизации компании не сразу смогут обеспечить полную защиту персональных данных, из-за слишком быстрых темпов перехода самой системы и структуры прежней экономики на новый уровень, и поэтому возникнет много проблем [6].

2. «Цифровое рабство».

С приходом цифровой экономики человек становится привязанным к своей банковской карте. Карту могут в любой момент заблокировать по определённому поводу или же просто по ошибке какого-то сотрудника и человек останется без денег, можно забыть Пин-код от карты и потерять возможность снять деньги в самый неподходящий момент или 
же мошенники каким-то образом снимут все сбережения с неё и кто-то, опять же, останется без денежных средств. Как нам всем известно, все, что подключено к Интернету можно взломать, что является огромным минусом для всех нас. Такие проблемы придется решать специалистам нового поколения, которым придется изобретать и создавать новые системы использования и защиты банковских карт, счетов и тому подобного. На такие инновационные процессы нужно время и, к сожалению, за это время подобных неприятных ситуаций произойдет очень и очень много.

3. Рост безработицы на рынке труда.

Большинство людей, которые просто заняты работой, требующей многократного повторения физических операций, будут освобождены от труда благодаря автоматизации производства. Уже есть заводы, где свет никогда не включается, потому что производство там полностью автоматизировано и роботам просто не нужен свет, чтобы выполнять работу, возложенную на них программой. Конечно, для огромной части населения это не станет поводом для радости, но избежать этого никак нельзя. Производство неизбежно будет автоматизировано, что, с одной стороны, снизит производственные издержки для работодателя, а с другой -оставит большинство людей безработными и заставит искать новые способы заработка. Уже сегодня уровень безработицы в разных регионах страны достаточно высок, но, к сожалению, со временем он будет только увеличиваться.

4. «Цифровой разрыв».

По своей сути, цифровой разрыв - ограничение возможностей социальной группы изза отсутствия у неё доступа к современным средствам коммуникации. Это явление невозможно избежать, ведь, например, пожилому человеку будет трудно перейти на покупку хлеба с доставкой через Интернет, если он всю жизнь покупал его через дорогу в магазине, мог увидеть его, понюхать, попробовать. Такой человек уже вряд ли перейдет к новым возможностям человечества. Также есть категория людей, которые не могут себе позволить гаджеты и, соответственно, не смогут воспользоваться Интернетом. На Кубе, допустим, нет доступа к всемирной паутине из-за политических взглядов, из-за чего люди там не смогут пользоваться всеми прелестями цифровой экономики еще очень и очень долго [7].

Таким образом, процесс цифровизации общества уже нельзя остановить, ибо он происходит. Последствия этого процесса могут быть самыми разными, некоторые экономисты говорят о цифровизации, как о новой цифровой революции, которая приведёт человечество к совершенно новому историческому этапу. Не исключено, что одной из первых стран, которая перейдет на новый экономический этап станет именно Российская Федерация.

В нашей стране достаточно возможностей, чтобы одними из первых перейти на цифровую экономику. Переход потребует высококвалифицированных специалистов из большинства сфер деятельности, инноваций и огромного объема работы. В нашей стране уже поддерживается национальный проект «Цифровая экономика», что свидетельствует о намерениях правительства страны в ближайшем будущем внедрить с 2021 по 2024 год стабильную и безопасную информационно-телекоммуникационную инфраструктуру для высокоскоростной передачи, обработки и хранения больших объемов данных, доступную для всех организаций и домохозяйств [8].

Начать использовать преимущественно отечественное программное обеспечение государственными органами, органами местного самоуправления и организациями, что является первым большим шагом нашей огромной страны в информационное будущее, тем самым повышая конкурентоспособность компаний [2].

$$
* * *
$$

1. Алетдинова А.С., Бабкин А.В. и др. Цифровая трансформация экономики и промышленности: проблемы и перспективы. / монография /Под ред.д-ра экон. наук, проф. А.В. Бабкина. - СПб: Изд-во Политехн. Ун-та, 2017. - 807 c.

2. Андиева Е.Ю., Фильчакова В.Д. Цифровая экономика будущего, индустрия 4.0 // Прикладная математика и фундаментальная информатика. - 2016. - № 3. - с. 214218. 
3. Бабкин А.В., Буркальцева Д.Д., Костень Д.Г., Воробьев Ю.Н. Формирование цифровой экономики в России: сущность, особенности, техническая нормализация, проблемы развития // Научно-технические ведомости СПбГПУ. Экономические науки. - 2017. - № 3. - с. 9-25.

4. Гапоненко А.Л., Савельева М.В. Традиционные и новые факторы конкурентоспособности организаций // Проблемы теории и практики управления. - 2019. - № 5. - с. 117-124.

5. Кунцман А.А. Трансформация внутренней и внешней среды бизнеса в условиях цифровой экономики // Управление экономическими системами: электронный научный журнал. - 2016. - № 11(93). - c. 1

6. Мухин, В. Н. Современные тенденции развития цифровой экономики и ее влияние на предпринимательскую деятельность / В. Н. Мухин. - Текст : непосредственный // Молодой ученый. - 2020. - № 48 (338). - С. 523 526.

7. Рогатных Е. Б. Влияние цифровизации на развитие современной мировой экономики // Экономика и управление: проблемы, решения. 2017.- № 11 Т. 5 C. 64-70.

8. Hughes G., Gareis K., Assis J., Cornford J., Richardson R. \& Sokol M. (2018). TRANSFORM: Benchmarking \& Fostering Transformative Use of ICT in EU Regions. Report TRANSFORM/Empirica. (EU FP6 - SSA; DG Infso).

\section{Стаурский С.С. \\ Особенности развития социальной сферы России}

Российская академия народного хозяйства и государственной службы при президенте РФ doi: 10.18411/trnio-12-2021-58

(Россия, Омск)

\section{Аннотация}

В статье рассматриваются особенности развития социальной сферы России, влияние которой сказывается на социально-экономическом развитии страны, качестве жизни населения. Кроме текущих проблем социально-экономического развития страны, распространение пандемии внесло свой вклад в развитие социальной сферы.

Ключевые слова: социальная сфера, социальная защита, социальная политика, социальное государство, социальные отношения.

\section{Abstract}

The article examines the peculiarities of the development of the social sphere of Russia, the impact of which affects the socio-economic development of the country, the quality of life of the population. In addition to the current problems of socio-economic development of the country, the spread of the pandemic has contributed to the development of the social sphere.

Keywords: social sphere, social protection, social policy, welfare state, social relations.

Современные источники литературы в понятие «социальная сфера» вкладывают несколько смысловых значений.

Самое распространенное понятие - это совокупность отраслей, предприятий, организаций, непосредственным образом связанных и определяющих образ и уровень жизни людей, их благосостояние, потребление. Социальная сфера по своему целевому назначению заключается:

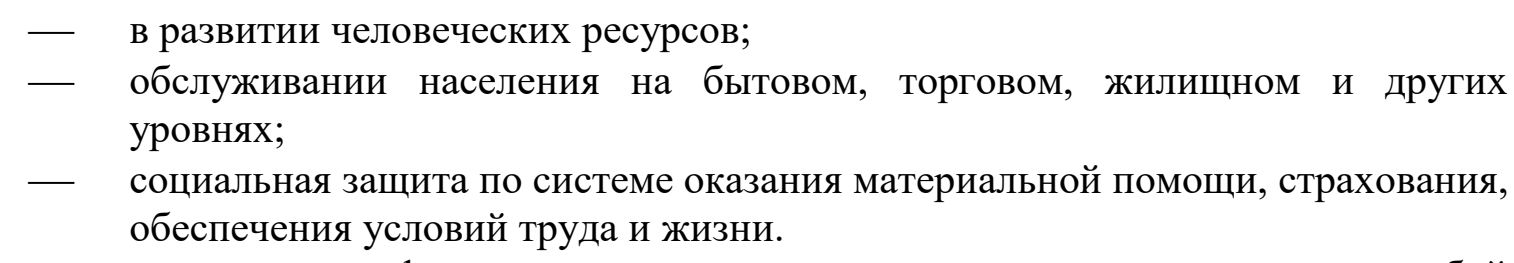

Понятия «социальная сфера» и «социальная политика» очень тесно между собой переплетаются. Обе категории взаимосвязаны - деятельность государства в социальной сфере выражается через социальную функцию. Социальная сфера связывается с областью жизнедеятельности человеческого общества, в которой реализуется социальная деятельность государства, общественных и религиозных организаций, благотворительных и 